\title{
¿QUÉ DEMOCRACIA TENEMOS? DEMOCRACIA REAL Y DEMOCRACIA LIBERAL REPRESENTATIVA
}

\author{
Carlos Gil de Gómez Pérez-Aradros ${ }^{1}$ \\ Universidad de Oviedo
}

http://dx.doi.org/10.5209/rev_NOMA.2013.v40.n4.48336

\begin{abstract}
La guerra es anterior al comercio; pues la guerra y el comercio no son sino dos medios diferentes de alcanzar la misma finalidad: el de poseer lo que se desea. El comercio no es sino un homenaje ofrecido a la fuerza del poseedor por el aspirante a la posesión. Es una tentativa para obtener paso a paso lo que no espera más que conquistar por la violencia. Un hombre que siempre fuera el más fuerte, no tendría jamás la idea del comercio. La experiencia le demuestra que la guerra, es decir, el empleo de su fuerza contra la fuerza del prójimo, lo expone a diversas resistencias y a diversos fracasos, y lo lleva a recurrir al comercio, es decir, a un medio más suave y más seguro de comprometer el interés de otro a consentir lo que conviene a su interés. La guerra es el impulso, el comercio es el cálculo. Pero por la misma debe venir una época en que el comercio reemplace a la guerra. Hemos llegado a esa época.
\end{abstract}

(Benjamin Constant: "Discurso sobre la libertad de los antiguos comparada con la de los modernos, 1819)

Resumen.- En los últimos años se ha ido haciendo hueco en la realidad socio-política el concepto de democracia real, arrastrado por los movimientos sociales pero generalizado en el lenguaje y práctica común. No obstante, este uso habitual del término parece estar vacío de contenido o, cuando menos, carente de una delimitación clara y concisa. Efectivamente, todos compartimos el deseo de una democracia real pero a todos nos resultaría definirla con precisión.

\footnotetext{
${ }^{1}$ Funcionario de Carrera perteneciente al Cuerpo Superior de Administradores del Principado de Asturias (Nombrado por Resolución de 5 de abril de 2011, de la Consejería de Administraciones Públicas y Portavoz del Gobierno, publicada en BOPA núm. 87 de 14-IV2011). Estudios de postgrado en el Doctorado de Relaciones Internacionales y Estudios Africanos de la Universidad Autónoma de Madrid (2001-2002). Licenciado en Ciencias Políticas y de la Administración por la Universidad Autónoma de Madrid (1999-2001). Curso Puente de la Licenciatura Ciencias Política y Sociología por la Universidad Nacional a Distancia (UNED) (1998-1999). Diplomado en Gestión y Administración Pública por la Universidad de Zaragoza (1995-1998). Publicaciones: (2011) Recensión. Las profecías autocumplidas de las sociedades del riesgo. REVISTA NÓMADAS. Revista Crítica de Ciencias Sociales y Jurídicas. Universidad Complutense de Madrid. ISSN 1578-6730, DL M-49272-2000; (2012) Artículo. La identidad como razón de Estado. REVISTA NÓMADAS. Revistas Crítica de Ciencias Sociales y Jurídicas. Universidad Complutense de Madrid. ISSN 1578-6730, DL M-49272-2000; (2012) Artículo. Elites, tecnócratas y ciudadanía: hacia una democracia con minúsculas. REVISTA NÓMADAS. Revistas Crítica de Ciencias Sociales y Jurídicas. Universidad Complutense de Madrid. ISSN 1578-6730, DL M-49272-2000; (2013) Libro. Reflexiones (poco académicas) sobre la sociedad actual. Oviedo. KRK Ediciones, 2013. 144 p. ISBN: 978-84-8367-410-9.
} 
Este trabajo pretende ser un estudio realista de qué tipo de democracia tenemos, partiendo de la evolución de las distintas corrientes (incluido el ideario republicano) que nos han llevado a compartir la democracia que vivimos en la actualidad. Todo ello nos llevará a replantearnos lo que tenemos pero no solamente desde la perspectiva del poder sino, y sobre todo, desde la posición del ciudadano que tiende a desatender los asuntos públicos.

Palabras Clave.- Democracia real, democracia liberal, virtudes cívicas, privado, público

Abstract.- In recent years it has been making space in the socio-political concept of real democracy, driven by social movements but widespread in language and common practice. However, the common use of the term seems to be meaningless, or at least, lacking a clear and concise manner. Indeed, we all share the desire for a real democracy but we all would be precisely defined.

This work intends to be a realistic study of what kind of democracy we have, based on the evolution of the various streams (including republican ideology) that led us to share the democracy that we live in today. This will lead us to rethink what we have but not only from the perspective of power, but, above all, from the position of the citizen who tends to neglect public affairs.

Keywords.- Real democracy, liberal democracy, civic virtues, private, public

Suele dejarse para momentos de crisis (económica, social, política, moral) el debate sobre la legitimidad u oportunidad del modelo democrático que compartimos. En los tiempos actuales no se ha producido una excepción por lo que han arreciado las críticas y los debates sobre si tenemos el mejor sistema democrático y si es conveniente o posible modificarlo. En buena medida, estas críticas adolecen de un soporte histórico y teóricos dejándose llevar por la crítica descarnada y las propuestas poco fundadas y practicables.

Algunos de estos movimientos, proponen medidas elogiables que demuestran el interés de parte de la sociedad en involucrarse por intentar, por medio de la participación, lograr un cambio en la política o la práctica política. No obstante, las propuestas, en ocasiones son poco practicables con el modelo democrático-institucional actual. Algunos de éstos podemos concretarlos en peticiones como el establecimiento de mecanismos efectivos que garanticen la democracia interna en los partidos políticos, Referéndums obligatorios para toda introducción de medidas dictadas desde la Unión Europea, supresión de gastos inútiles en las Administraciones Públicas y establecimiento de un control independiente de presupuestos y gastos, expropiación por el Estado de las viviendas construidas en stock que no se han vendido para colocarlas en el mercado en régimen de alquiler protegido, ... 
La idea de este artículo es hacer un breve repaso por la evolución y construcción del modelo democrático actual (compartido en occidente e importado, con mayor o menor éxito, al resto del planeta) así como concretar una serie de características de esta nuestra democracia que se ponen en tela de juicio por movimientos sociales que reaccionan frente a ella, así como la dificultad o imposibilidad de implementar buena parte de estas demandas con los modelos actuales y con el exilio voluntario de buena parte de la ciudadanía.

No encontraremos ninguna reflexión, artículo o escrito en general dedicado a la democracia que no comience por la Grecia clásica. Buena parte de los términos que aún hoy se utilizan proceden de aquella época, si bien, como veremos, nunca más se ha reproducido experiencia tal, ha sido criticada durante siglos y rechazada su denominación y sustituida por un término más adecuado como es República. Por si fuera poco, estudios más o menos recientes han constatado que determinadas instituciones y prácticas ya eran utilizadas en el pasado, pudieron ser importadas de otras culturas previas. En todo caso, la Grecia clásica de los siglos VI y V son el comienzo de todo el proceso que ha desembocado en nuestros días.

Lo cierto es que aún cuando muchas deben ser las precisiones y concreciones de este comienzo, una debe ser tenida en cuenta por encima de todas ellas: la extensión de la posibilidad de participar en los asuntos públicos. Dicho de otro modo, el reducido número de personas que podían hacer usos de sus derechos a la participación en la Polis, hacen de aquélla, una realidad, que a nuestros ojos, se aleja del ideario democrático. Aunque no debemos olvidar que a su entender, nuestros modelos democráticos poco tendrían que ver con su concepción de la democracia.

Con todo y con esto, la democracia de la antigua Grecia ha sido y es la referencia a una democracia pura e ideal y, a la vez, el centro de las críticas a este modelo puro de gobierno. Prácticas como la democracia directa, el sorteo de cargos 0 los jurados populares eran habituales fomentando una participación directa, sin intermediarios, en los asuntos públicos que afectaban a todos los habitantes de la Polis. El ejercicio de la parcela de soberanía se ejerce de modo directo, personal e intransferible, sin representación de colectivos o ciudadanos, sin encorsetamientos ideológicos o institucionales. Tucídides, en su discurso fúnebre de Pericles ilustra esta realidad:

Disfrutamos de un régimen político que no imita las leyes de los vecinos); más que imitadores de otros, en efecto, nosotros mismos servimos de modelo para algunos. En cuanto al nombre, puesto que la administración se ejerce en favor de la mayoría, y no de unos pocos, a este régimen se lo ha llamado democracia); respecto a las leyes, todos gozan de iguales derechos en la defensa de sus intereses particulares; en lo relativo a los honores, cualquiera que se distinga en algún aspecto puede acceder a los cargos públicos, pues se lo elige más por sus méritos que por su categoría social; y tampoco al que es pobre, por su parte, su oscura posición le impide prestar sus servicios a la patria, si es que tiene la posibilidad de hacerlo.

Pero esta participación en los asuntos de la Polis, este ejercicio de la Política con mayúsculas, circunscribía, no sólo lo Público sino también lo privado, deslindando claramente dónde empezaba uno y acababa otro. Este hecho 
permitía defender los intereses comunes y los intereses individuales en foros distintos.

Hoy en día no resulta sencillo reconocer esta bipolaridad de intereses, ni este vínculo cívico. Mucho tuvo que ver la división administrativa de la Polis en demoi que agrupaba a ciudadanos sin más afinidad que la participación en la vida pública, sin otro valor o criterio que pudiese nublar la búsqueda de interés común frente a interés concreto y específico que cada uno de los ciudadanos dejaba de puertas hacia dentro.

El punto de partida, como casi cualquier modelo político-social es de origen contractualista, pero no al modo liberal sino a la inversa. Es la Polis la que crea a los animales políticos, la que permite el establecimiento de la esfera de lo público y que, sólo después, permitirá la búsqueda de los intereses egoístas de cada uno. No es el individuo, racional o no, en constante estado de guerra o no (Hobbes o Rousseau) el que crea la sociedad y la política en provecho propio, como parapeto para la búsqueda de sus propios intereses. Para la concepción clásica o antigua la sociedad política es consustancial al individuo, no es una creación artificiosa en beneficio de intereses previos e intrínsecos a él.

Lo más paradójico de lo dicho hasta aquí es que sólo los Sofistas fueron unos sinceros defensores de este modelo ideal o puro, frente a Socráticos, Platónicos o Aristotélicos, que consideraban a este modelo como viciado o abiertamente peligroso. Aquéllos, con una visión antropológica de lo más optimista, incitan al individuo a contribuir en los asuntos públicos, otorgándoles una igualdad de juicio y asumiendo una pluralidad de opciones y respuestas.

Todo giraba en torno a la vida pública, frente al aislamiento del individuo liberal que considera esta vida pública un mal necesario. No podría entenderse al individuo sin esta participación. Participación directa, no debemos olvidar, sustanciada en la Asamblea, sin instituciones tales como la Iglesia, Ios partidos políticos o los grupos de presión de diferente índole. No son los intereses privados lo que llevan a la política sino al contrario, ya que sin ámbito común y público, no cabría plantearse ningún interés privado. Hasta el punto de que los intereses privados debían ser reconocidos por la Polis, alejando el dicho de lo que los vicios privados conllevan virtudes públicas...De este modo, nos recuerda Aristóteles, aun siendo crítico con la Democracia frente a la República:

El hombre, es por naturaleza, un animal cívico [...] La razón de que el hombre sea un ser social, más que cualquier abeja y que cualquier otro animal gregario, es clara. La naturaleza, pues, como decimos, no hace nada en vano [...] La participación comunitaria en ésta funda la casa familiar y la ciudad.

La vida política, entendida como vida pública y común, no es otra cosa que la vía para la autorrealización. Sólo por este vía se llega a ser un individuo autónomo, a diferencia, una vez más del ideario liberal, donde la libertad se disfruta al margen de cualquier injerencia pública. La actuación pública y la realización cívica era la medida de la libertad, no habiendo nada peor que el ostracismo político. Nada se decía de la necesidad de leyes que garantizan los derechos previos (carentes de sentido al margen de la Polis) como garantes de 
una libertad o una autorrealización plena. Sólo el autogobierno y la toma de decisiones eran el camino de la libertad. En definitiva, el ciudadano se define por su acción política, única y exclusivamente, al margen de cualquier derecho o acción previo y/o privado.

En todo caso, tras este brevísimo repaso por la concepción del tipo de democracia clásica, urge advertir que lo que hoy llamamos democracia no es otra cosa que el resultado de una serie de circunstancias históricas y que compartimos esta forma de gobierno como podíamos compartir otra. No obstante, convendrá retener lo dicho hasta ahora, por cuanto se convertirá en clave para el devenir democrático posterior pues serán sus críticas, más que sus apoyos, las que irán conformando el modelo actual.

De hecho, como ya advertimos, aún cuando hayamos elegido textos generosos con la democracia, la mayor parte de los escritos que nos han llegado, clásico y posteriores, son poco partidarios con el gobierno del pueblo, por peligroso y partidista, primero y por imposible después, entre otros razonamientos.

Incluso terminológicamente, la palabra democracia era sustituida por república, si bien, esta última posee características propias. Estas características, ampliamente desarrolladas hasta nuestros días, se pueden resumir en cinco:

- soberanía popular

- representatividad

- participación política.

- igualdad.

- gobierno mixto.

Lo cierto es que el ideal republicano poco tiene que ver con la concepción clásica de democracia, aún cuando algunos escritos tienden a identificar, a lo largo de la historia una y otra. Principalmente, los autores republicanos clásicos (comenzando por Aristóteles) no consideraban una participación política como medio de autorrealización pública sino más bien como una participación utilitarista, en tanto en cuanto, sólo se debía participar si se tenía algo útil que aportar...Vemos como la consideración del actual político se convierten en una acción elitista (tanto aportas, tanto vales).

Junto a esta realidad (o tal vez como consecuencia de ella) la parcela de soberanía de cada ciudadano no puede ejercerse de modo personal sino, únicamente, a través de terceros.

Por lo que respecta a la igualdad, ésta va poco más allá de una tendencia al sufragio cada vez más amplio, poco tiene que ver con una igualdad material o de derechos. Todos (excluyendo a una amplia mayoría de la población) pudiendo participar por medio del sufragio tendrán las mismas posibilidades de decisión en los asuntos públicos (sin olvidar que la participación debe aportar algo valioso a la comunidad, algún tipo de valor añadido, utilizando terminología más actual).

Y claro está, el gobierno mixto reparte el poder en diferentes clases evitando la asunción total del mismo y evitando a la vez el gobierno de todos (del pueblo). 
Vemos cómo democracia y republicanismo parten de realidades distintas pero tienden a vincularse por preocupaciones comunes, sustancialmente, la participación por medio de representantes, la preocupación por establecer límites al poder y el fomento de una ciudadanía virtuosa y fuerte.

No obstante, aún cuando se haya podido producir un cierto mimetismo o absorción entre una y otra tradición política (la democrática y la republicana) no es menos cierto que hoy en día poco tiene que ver la realidad del ideario republicano clásico y la realidad actual, por motivos que intentaremos desgranar a los largo de estas líneas. Podemos adelantar algunas reflexiones como son el escaso impacto en la actuación cívica del carácter social del ser humano, la búsqueda de virtudes cívicas frente a los intereses privados o la preeminencia de la igualdad material frente a la isonomía o la isegoría.

Un heredero de este republicanismo clásico, Nicolás Maquiavelo, consideraba que sólo de la realidad (frente a la ideal), de la empírica (frente a lo normativo) fortaleza de los gobiernos procede la ley y con ella la justicia y la libertad. Todo ello está por encima de cualquier otra circunstancia.

Pero, siendo mi propósito escribir algo útil para quien lo lea, me ha parec ido más conveniente irdirectamente a la verdad real de la cosa que a la $r$ epresentación imaginaria de la misma. Muchas se han imaginado repúblicas y principados que nadie ha visto jamás ni se ha sabido que existieran realmente; porque hay tanta distancia de cómo se vive a cómo se debería vivir, que quien deja a un lado lo que se hace por lo que se debería hacer, aprende antes la ruina que su preservación: porque un hombre que quiera hacer en todos los puntos profesión de bueno, labrará necesariamente su ruina entre tantos que no lo son.

No obstante, para un segundo heredero de este modelo, J.J.Rouseau, la justicia, la libertad y la igualdad sólo se producen al evitar el gobierno representativo, por medio del cumplimiento de la ley como expresión de la autodeterminación del sujeto colectivo. La libertad como motivación última del grupo social, frente al fortalecimiento del poder político y la extrapolación de modelos normativistas a realidades existentes.

Si se investiga en qué consiste el bien más grande de todos, el que debe ser la meta de todo sistema legislativa, veremos que consiste en dos cosas principales: la libertad y la igualdad. La libertad, porque si permitimos que alguien no sea libre estamos quitando fuerza al Estado; la igualdad, porque la libertad no puede subsistir sin ella. Ya se ha dicho lo que es la libertad civil. En cuanto a la igualdad, no hay que entender por ella que todos tengan el mismo grado de poder y de riqueza [...] que ningún ciudadano sea tan rico como para poder comprar a otro, ni ninguno sea tan pobre como para ser obligado a venderse.

En definitiva, el republicanismo, no entendido como una mera y simple oposición a la monarquía, ha sido fagocitado por el Estado moderno (persecución de la corrupción y fortaleza del Estado), en un primer término, y 
por su implementación práctica (paradigmáticamente en los EE.UU.) ya en la etapa contemporánea, en segundo lugar, (división de poderes, federalismo rígido y gobierno representativo). Cómo veremos, una de las virtudes más destacadas de la democracia liberal es su capacidad para hacer suyas aspectos que de origen no le son propios pero que por razones históricas ha tenido que asumir para no verse superada. No obstante, la realidad social, sus cambios, también han reducido la posibilidad de participación directa en los asuntos públicos, la superación de la sociedad estamental ha multiplicado los intereses de la comunidad y los estados prestacionales han terminado por acabar por búsqueda de la virtud cívica y la ciudadanía fuerte.

Suele considerarse doctrinalmente dos tipos de democracia: al antigua, que hemos visto hasta ahora y la moderna, heredera de la tradición liberal. Ésta es la que compartimos en la actualidad, con modulaciones, y la que se ha tratado de exportar a todos los rincones del mundo...con más fracaso que éxito.

Lo primero que debe llamarnos la atención es el carácter contradictorio de los conceptos que vamos a utilizar conjuntamente (liberal y democracia) por cuanto para el liberalismo clásico la participación directa de los ciudadanos en los asuntos públicos es imposible e indeseable y por cuanto la legitimidad no surge de la participación en los asuntos públicos sino en el consentimiento, el imperio de la ley, la división de poderes y el respeto de los derechos naturales individuales, desconocidos para la democracia clásica.

Durante los siglos XVIII y XIX se intentó llevar a cabo una adaptación de las concepciones heredades de la antigüedad pero en la práctica resultó una verdadera revolución. Trataron, además, de corregir los defectos observados en el pasado (curiosamente, prácticamente, todos los texto que se han conservado son contrarios a la democracia, por lo que resulta irónico que se pretendieran corregir errores del pasado) sobre todo los relativos a la inconveniencia de la participación directa del ciudadano. No solamente no era posible hacerlo en el nuevo marco de las comunidades modernas (grandes y ricas sociedades comerciales) sino que no era oportuno ni adecuado hacerlo. Este tipo de nuevas estructuras crecen al calor de los intereses privados, acciones egoístas que buscan el enriquecimiento individual, alejándose de cualquier atisbo comunitario. La búsqueda de grandes empresas personales, en el ámbito de lo económico, comienzan a poner en duda la búsqueda de la acción pública, de la participación como proceso de acceso a la virtud pública. Este capitalismo emergente encaja a la perfección con la concepción liberal de que sólo los más capaces deben ocupar cargos públicos, elegidos periódicamente por una parte de la sociedad cada vez más amplia, convirtiéndose este acto en una de las pocas formas de participación (situación que no ha cambiado demasiado con el devenir de los siglos...). Los liberales rechazaban la democracia antigua (el gobierno de los muchos) por ser peligrosa al no permitir el control del poder, un miedo que se pretende superar por medio de la división (de poderes -Ejecutivo, Legislativo y Judicial-, del territorio -Federelismo-, de la sociedad -gobernantes y gobernados-). Esta última separación es la que nos interesa, en la medida en la que separa a una pequeña parte que gobierna (los que más saben, las elites) y una inmensa mayoría que se deja gobernar (a cambio de elegir periódicamente a esta casta). Pero sobre todo a cambio de que sus derechos individuales y sus intereses privados no les sean vulnerados, ni siquiera afectados por ningún 
interés general. Tal vez Benjamin Constant fue el que mejor identificó este hecho.

Jamás su voluntad se marca sobre el conjunto; nada constata su cooperación ante sus propios ojos. Así pues, el ejercicio de los derechos políticos no nos ofrece sino una parte de los goces que los antiguos encontraban en ellos, y al mismo tiempo los progresos de la civilización, la tendencia comercial de la época, la comunicación de los pueblos entre sí, han multiplicado y variado hasta el infinito los medios de felicidad particular.

Resulta de ello que debemos estar mucho más ligados que los antiguos a nuestra independencia individual. Pues los antiguos, cuando sacrificaban esta independencia a los derechos políticos, sacrificaban menos para obtener más; mientras que haciendo el mismo sacrificio nosotros daríamos más para obtener menos.

La finalidad de los antiguos era compartir el poder social entre todos los ciudadanos de una misma patria. Estaba ahí lo que ellos llamaban libertad. La finalidad de los modernos es la seguridad de los goces privados; y ellos llamaban libertad a las garantías acordadas a esos goces por las instituciones.

Autonomía y autorrealización se obtienen en el ámbito de lo privado y no de lo público y esta pluralidad de intereses convierte a la política en una competencia por la defensa de los mismos. Veamos algunas pequeñas referencias de los clásicos:

Para comprender bien en qué consiste el poder político y para remontarnos a su verdadera fuente, será forzoso que consideremos cuál es el estado en que se encuentran naturalmente los hombres, a saber: un estado de completa libertad para ordenar sus actos y para disponer de sus propiedades y de sus personas como mejor les parezca, dentro de los limites de la ley natural sin necesidad de pedir permiso y sin depender de la voluntad de otra persona.

(John Locke, Segundo tratado sobre el gobierno)

Cuando los poderes legislativo y ejecutivo se hallan reunidos en una misma persona o corporación, entonces no hay libertad, porque es de temer que el monarca o el senado hagan leyes tiránicas para ejecutarlas del mismo modo. Así sucede también cuando el poder judicial no está separado del poder legislativo y del ejecutivo. Estando unido al primero, el imperio sobre la vida y la libertad de los ciudadanos sería arbitrario, por ser uno mismo el juez y el legislador y, estando unido al segundo, sería tiránico, por cuanto gozaría el juez de la fuerza misma que un agresor 
No es libre ninguna sociedad, cualquiera que sea su forma de gobierno, en la cual estas libertades no estén respetadas en su totalidad; y ninguna es libre por completo si no están en ella absoluta y plenamente garantizadas. La única libertad que merece este nombre es la de buscar nuestro propio bien, por nuestro camino propio, en tanto no privemos a los demás del suyo o les impidamos esforzarse por conseguirlo. Cada uno es el guardián natural de su propia salud, sea física, mental o espiritual. La humanidad sale más gananciosa consintiendo a cada cual vivir a su manera que obligándole a vivir a la manera de los demás.

(John Stuart Mill. Sobre la libertad)

Era imposible fijar de antemano, de una manera exacta y completa, la parte de poder que debía corresponder a cada uno de los dos gobiernos entre los que la soberanía iba a repartirse. ¿Quién podría prever con anticipación todos los detalles de la vida de un pueblo? Los deberes y los derechos del gobierno federal eran simples y bastante fáciles de definir, porque la Unión había sido formada con el fin de responder a algunas grandes necesidades generales. Los deberes y los derechos del gobierno de los Estados eran, al contrario, múltiples y complicados, porque ese gobierno penetraba en todos los detalles de la vida social.

(Alexis de Tocqueville, La democracia en América)

A este modelo, se lo oponen al menos dos discursos, el de la crítica elitista de la democracia (al que hicimos referencia en la parte final del Capítulo relativo a la tecnocracia) y el de la democracia radical, ante el que nos detendremos brevemente. Su primera crítica responde a algo bastante evidente: el déficit democrático que plantean las democracias-liberales. La simple cita electoral para elegir a nuestros representantes no parece suficiente como sinónimo de ejercicio de acción cívica.

Por otra parte, hemos llegado a una sociedad muchos más injusta y deshumanizada, alejada del Estado natural concebido a modo Rouseauniano al que no podemos volver pero sí recuperar su esencia por medio de la educación cívica.

Además, la libertad, fin más alto para el ideario liberal, no se disfruta en el ámbito privado, ni se obtiene por medio de la participación directa, sino por el sometimiento a la voluntad general, de este modo, uniéndome a todos no obedezco más que a mí mismo.

Ahora bien, aun cuando estos argumentos parecen tan actuales como lógicos no es menos cierto que resultan sencillos de desmontar. La participación política por medio del sufragio tal vez no sea suficiente, pero resulta, a veces, complicado implicar a los ciudadanos en asuntos públicos, exigirles una mayor implicación si no van a obtener algún tipo de rédito individual e inmediato.

Por lo que respecta a la educación cívica parece más complicado lograr un acuerdo común de todos los representantes políticos sobre este tema que aplicarla en la sociedad. No es necesario recordar las desavenencias relativas a las Leyes Orgánicas de Educación en España desde la instauración de la 
democracia (e incluso antes) y la práctica común de cambiar el modelo anterior cada vez se produce un cambio de gobierno.

Y por último, hablar hoy en día de voluntad general suena a restricción de la voluntad particular. Tal vez, y sólo tal vez, podemos encontrar una única voluntad en sociedades muy homogéneas, con intereses comunes vitales, que estén dispuestas a subordinar sus beneficios a los de la comunidad, algo que parece difícil encontrar en la actualidad...Además, la voluntad general, concretada en leyes abstractas y generales obtenidas por medio de un procedimiento legislativo, no es tan si sólo algunos de los representantes políticos legislan o lo hacen con la vista puesta en intereses electoralistas o de partido o se pone el discusión el procedimiento legislativo (muy recomendable la lectura de Habermas sobre la justicia procedimental).

En todo caso la democracia-liberal clásica, como hemos advertido ya, tiene la capacidad de adaptarse a los cambios operados en historia pero mantiene, en lo esencial, sus rasgos distintivos. El devenir del Estado moderno con el crecimiento de la población, sus guerras de religión (allí donde llegaron) o su concentración de poder, encajó con el modelo liberal, lo que no creó directamente. Pero conviene detenerse en un factor clave para el devenir de la construcción de la democracia-liberal tal y como la conocemos ahora, que no es otro que el surgimiento de un proto-capitalismo que supera y las concepciones clásicas y medievales desde diversos puntos, no solamente económicas. La actividad mercantil que comienza a principios del siglo XVI y XVII van a dar un giro a al concepción cívica separando, definitivamente, la vida pública, mínima, de la vida privada, de la actividad económica y familiar. Se produce un giro hacia lo íntimo, de lo comunitario a lo individual. En este contexto, el Estado debe cumplir varios labores (concepción funcionalista) que lo convierten, frente a las concepciones antiguas, en un fin en sí mismo, frente al medio que pudo ser en el pasado (de haber existido) para facilitar las bases necesarias que permitan realizar un vida pública plena. Mantendrá una situación de paz que garantice las actividades comerciales, los derechos individuales, la igualdad, pero poco más debe hacer.

Podemos vincular este extremo en el origen mismo de las sociedades anónimas y en menor medida en las sociedades de responsabilidad limitada. Por lo que respecta a las primeras su origen está ligado a las compañías creadas en el siglo XVII para el comercio con las Indias orientales y occidentales. Los grandes descubrimientos geográficos de los siglos anteriores abrieron nuevas rutas al comercio y crearon un clima favorable para el montaje de grandes expediciones y empresas comerciales que, por su importancia y por los grandes riesgos inherentes, no podían ser acometidas por las compañías tradicionales (colectiva y en comandita) de ámbito cuasifamiliar, de muy pocos socios ligados por vínculos de confianza recíproca y de responsabilidad ilimitada. Excedían, incluso, esas empresas de los recursos y poderes de los Estados, y cuajó entonces la idea de constituir compañías con el capital dividido en pequeñas partes alícuotas, denominadas acciones, como medio de facilitar la reunión de los fuertes capitales necesarios para llevar a cabo esas empresas, atrayendo hacia ellas pequeños capitales privados y repartiendo entre muchos partícipes los ingentes riesgos del comercio colonial. Vemos cómo el propio Estado fomentaba este tipo de actividad comercial individual, extendiendo su poder por el mundo y apoyando a la una emergente burguesía 
que apoyaba al gobernante con el único fin de que les permitiera realizar dichas actividades.

Pero estas primitivas compañías eran muy distintas de las actuales sociedades anónimas. Eran entidades semipúblicas, constituidas directamente por los soberanos mediante decisiones gubernativas (octroi) que las dotaban de personalidad y les conferían privilegios monopolísticos en la explotación comercial, al propio tiempo que solían reservar al poder público una participación en los beneficios y una intervención o control constante en los asuntos sociales. Con el único fin de enriquecerse, los Estados apoyaron a este grupo social emergente transformando la relación con el poder bajo la máxima de protección y paz para la realización de sus transacciones a cambio de apoyo incondicional a los Estados modernos y contemporáneos. Pero el triunfo de las revoluciones burguesas impedirá, junto con otros factores, plantear una vuelta a la preeminencia de lo público frente a lo privado. Es el propio Estado el que no busca a ciudadanos activos socialmente, más al contrario, protegen y fomentan su ámbito personal.

La evolución hacia la forma actual de la sociedad anónima se inicia a partir de la Revolución francesa bajo la presión de los postulados del capitalismo liberal. En el Código de comercio napoleónico la sociedad anónima, separada del Estado, ya no se funda por octroi, sino por voluntad de los socios, sin perjuicio de quedar supeditada a la previa concesión o autorización gubernativa, como medida de control de la legitimidad y de la conveniencia de su creación. Nuestro Código de 1829, más progresivo que el francés, se limitó a exigir la aprobación de las escrituras fundacionales por los Tribunales de comercio, y en él aparece ya, privatizada, la sociedad anónima en todo lo relativo a su organización y funcionamiento; desaparecen los privilegios, desaparece la injerencia del Estado en la vida social, y ésta se va a regir democráticamente por la voluntad de los socios en régimen de igualdad de derechos (estas autorizaciones desaparecerán definitivamente en el siglo XIX).

En definitiva, el individuo es un sujeto activo en la vida privada (el protestastimos en este punto legitima este extremo desde un punto de vista sacro, como nos advierte Max Weber) y pasivo en la esfera pública, cada vez menos importante. Conviene destacar cómo es el propio ciudadano el que comienza a despreciar la vida pública, que aparentemente otorga menos rédito que la vida privada (familiar y empresarial). El sufragio restringido parece ser la única forma de acción pública, que se ampliará posteriormente con el movimiento obrero, sindicalismo, partidos políticos...

A estos cambios, junto con otros como el desarrollo de la tecnología, la burocratización, el sufragio universal, ampliación de los derechos civiles, la preeminecia de los partidos políticos, se adapta la democracia-liberal transformando a los Estados en prestadores o en garantistas del bienestar social, sobre todo tras la segunda posguerra mundial.

Es entonces cuando el discurso liberal se enfrenta a esta inevitable extensión de los tentáculos del Estado, cuyos fines se amplían exponencialmente. La reacción es pendular entre un liberalismo negativo y mínimo, representado por Hayek, y un liberalismo más social, menos minimalista, representado por Berlin. En todo caso, la práctica política y la participación también tiende a transformarse como consecuencia de nuevos derechos sociales, 
burocratización creciente que lleva aparejada el Estado de Bienestar, tecnologización de la vida, impacto de los medios de comunicación de masas o la globalización de todos los ámbitos de la sociedad.

En este punto comienzan a depurarse nuevas prácticas políticas e institucionales que obligan a replantearse realidades nacidas en el pasado pero adaptadas al presente: si existe una separación de poderes saludable para la vida democráticas, si la injerencia del ejecutivo en el resto de poderes es adecuada, si los partidos políticos, internamente, actúan de una forma democrática, el escaso peso de la oposición en el actuar político, el mandato imperativo como sumisión a una determinada familia dentro de los partidos, ... El contexto cambia y la democracia-liberal parece adaptarse mediante el intento de control o adopción de la información, de los movimientos sociales, de las decisiones técnicas o del propio sector público como propiedad exclusiva y excluyente.

No vamos a detenernos en la crítica elitista de la democracia, pero sí en la crítica pluralista que no considera la existencia de una única elite dominante sino de una pluralidad de grupos sociales dominantes $y$, por naturaleza, heterogéneos. Este hecho sitúa el centro de gravedad de las decisiones políticas en múltiples lugares lo que obliga a los gobernantes ( $y$ antes, a los potenciales elegibles) a evaluar el interés de estos focos de interés en función del número de miembros, de su capacidad de movilización social, de su recursos económicos, de la intensidad de sus preferencias, de su intención de desestabilizar el sistema, de sus apoyos externos o cualquier otros factor que pueda incidir en el acceso al poder o en el mantenimiento del mismo.

Por su parte, la desideologización de las sociedades y de los partidos políticos (simplificada en la teoría del heladero) convierte a éstos en unas agrupaciones que pretenden asumir la "representación" de un mayor número de ciudadanos al margen de su ideología. El apoyo puntual se antepone a una fidelidad a las siglas, circunstancia que los partidos agradecen fervientemente...Incluso son capaces de tratar de aglutinar colectivos y movimientos que se oponen a ellos. El cálculo, el pragmatismo y la búsqueda del voto mueven a los partidos. La comodidad, el bienestar individual y la búsqueda de la tranquilidad pública mueven a los ciudadanos.

Lo que quiero destacar no es sólo una crítica hacia el actual modelo poltícoinstitucional sino también cómo la separación entre la vida pública y privada coloca al ciudadano en una confortable situación de no injerencia (en lo propio y ajeno) y de inacción (en lo colectivo). La mínima participación en los asuntos de la polis nos aleja de sus decisiones $y$, aparentemente, de sus responsabilidades, sin renunciar a las prestaciones que se nos brindan y sólo exigiéndolas cuando disminuyen o desaparecen.

No obstante, esto no quiere decir que podamos ni debamos rescatar prácticas pasadas, amparadas en un ejercicio supremo de la soberanía. Ni se puede ni, tal vez, se pueda. La isegoría no es factible ni desde un punto cualitativo (millones de personas opinando y siendo escuchados) ni cualitativo (materias complejas e inaccesibles) pero tampoco resultaría sencillo "obligar" a toda la ciudadanía a participar. El liberalismo, como hemos visto, no acepta ninguna injerencia en la vida del individuo, ni siquiera aquella que pueda reportarle 
mayores beneficios. Además, hoy en día, el ostracismo no es visto como algo negativo, más bien al contrario.

Frente a consideraciones de igualdad de juicio político y de criterio público, como hemos visto, tanto el republicanismo como el elitismo democrático, entre otras corrientes, no consideran tal igualdad, lo que impide considerar a toda la ciudadanía por igual, encontrado desigualdades que no discriminaciones. El sistema, tal y como se ha ido configurando, reconoce estas desigualdades, incluso las fomenta.

Lo que parece evidente es que la democracia, como participación, se ha ido debilitando desde su etapa clásica, como participación directa, pasando por la representativa hasta una pretendida democracia global, que difumina todavía más la participación en los asuntos públicos. Los avances tecnológicos, la red, no has sido capaces de fortalecer los elementos definitorios del sistema, más bien han excluido a un importante sector de la sociedad, aspecto que no podemos olvidar, además de proporcionar una cantidad ingente de información que lejos de facilitar, dificulta la concreción y la solución de los asuntos.

Las virtudes públicas y una ciudadanía fuerte has dejado paso a una preeminencia de los asuntos privados, dentro de un marco prestacional y de búsqueda de una igualdad material, mucho más tranquilizador y relajado para una inmensa clase media que jugaba (o jugábamos) a ser lo que no éramos, sin preocuparnos por los común, lo general. Todo aquello que no nos daba un rédito inmediato y económico.

La democracia, de este modo configurada a lo largo de la historia ya no es un mecanismo de acuerdos y pacificación política, como debería ser. Más bien se ha convertido en un ideal abstracto e incuestionable, poco práctico y alejado, que se utiliza en el lenguaje de propios y extraños, sin una posibilidad real de cambiar algo forjado a lo largo de siglos y mucho menos sin un empeño y esfuerzo real por cambiarlo. Los medios de comunicación, los corrillos de cualquier centro de trabajo, los cafés o las cañas, son testigos y amplificadores de una desazón creciente, sin una verdadera acción colectiva coordinada que pueda mediatizar algo, si es que eso es posible. Todos queremos cambiar las cosas pero nadie está dispuesto a anteponer lo suyo por lo de todos. Y todo responde a la ausencia de un bien común identificable e identificado, cuando lo que existe es un bien por cada individuo atomizado, que no suele anteponerlo al suyo propio.

El individuo autónomo y racional es catalogado como ciudadano, ahora bien, debe ser un buen ciudadano, todo lo que no sea así, será improcedente. Los espacios públicos que servían en el pasado para conformar una opinión común, debatir y buscar puntos en común se han convertido en un lugar moral donde se enseñan buenas prácticas ciudadanas, como nos recuerda Manuel Delgado. La masa (incluidas las movilizaciones sociales actuales) irracional debe convertirse en ciudadanos racionales, por lo que los mecanismos pedagógicos y coactivos deben facilitar la conversión (todos tenemos en la retina la contundencia de los desalojos de viviendas o plazas públicas). El civismo y otras abstracciones indiscutibles tendrán lugar únicamente cuando se den un conjunto de "adecuadas" prácticas. Nada más lejos de las conductas que estamos viendo en tiempos recientes contra los recortes en sanidad, desalojos de viviendas, preferentes, corrupción política y un largo etcétera. Los 
conductos para hacerse oír o proponer un bien común son escasos y poco adecuados, según reconoce le propio sistema político, pero aún peor es la movilización social.

Estos movimientos hacen entrar en contacto a un amplio número de personas con inquietudes comunes en el ámbito de lo público, dejando de ser animales privados y egoístas, poniendo en peligro la concepción burguesa de masa silenciosa, que actúa más por sus fines que por otros motivos. Por ello se trata de adecuar la conducta, según criterios neutros, a buenas prácticas cívicas, desprestigiando cualquier solicitud o acción colectiva.

Estos movimientos sociales adoptan formas no convencionales y espontáneas (acciones ciudadanas cada vez más habituales) intentando escapar de cualquier encasillamiento ideológico-institucional, aunque a veces nos recuerden a dogmas concretos. Pero actúan de modo muy intenso para volver al anonimato, al remanso de lo privado, donde todo esfuerzo conlleva un beneficio propio. Nos encontramos ante un comunitarismo individualista, una acción directa seguida de una autocomplacencia hedonista, a la espera de otra acción puntual y reivindicativa. Una acción política al margen de la política...

De este modo se produce un desinterés por la política, amparado por nuestros políticos (por cierto, doscientos de ellos implicados en causas de corrupción en sólo cinco Comunidades Autónomas, a principios de 2013) que sólo buscan movilizar a las masas en el momento electoral... Salvo por una minoría idealista que, paradójicamente, parece legitimar lo que critica. Y así lo parece cuando realizan propuestas que terminan debatiéndose en el Legislativo (durante largo tiempo) o incluyéndose en programas electorales. De este modo se institucionalizan, del modo que más conviene, para dejarse morir en la orilla. Las leyes de transparencia, las acciones contra los desahucios o las medidas para solventar el problema de las preferentes son algunos temas que han terminado en las agendas de los líderes políticos y que no pasarán de ahí, de normas programáticas o compadreos con grandes grupos de interés.

\section{OBRAS CONSULTADAS}

(1983) ARISTÓTELES, La política; Espasa-Calpe, Madrid.

(2009) TUCÍDIDES, El discurso fúnebre de Pericles, Seguitur, Madrid.

(1961) MAQUIAVELO, Nicolás, El príncipe; Espasa-Calpe, Madrid.

(1986) ROUSSEAU, Jean-Jacques, Del contrato social; Discurso sobre las ciencias y las artes; Discurso sobre el origen y los fundamentos de la desigualdad entre los hombres; Alianza, Madrid.

CONSTANT, Benjamin, Discurso sobre la libertad de los antiguos comparada con la de los moderno; Constitución Web, constitucionweb.blogspot.com.es

(1990) LOCKE, John, Según tratado sobre el gobierno civil; Alianza, Madrid.

(1972) MONTESQUIEU, Chales-Louis de Secondat, Barón de, El espíritu de las leyes; Tecnos, Madrid.

(1984) MILL, John Stuart, Sobre la libertad; El utilitarismo; Orbit, D.L., Barcelona.

(1990) TOCQUEVILLE, Alexis de, La democracia en América; Aguilar, Madrid.

(2011) DELGADO, Manuel, El espacio público como ideología; Los libros de la catarata, Madrid. 